\title{
A VISIBILIDADE TRANSGÊNERO NO INSTAGRAM
}

\section{TRANSGENDER VISIBILITY ON INSTAGRAM}

Lucíola Carla Correia da Silva ${ }^{1}$

1 Centro Universitário Maurício De Nassau, Departamento de Comunicação Social, Recife - PE, Brasil, e-mail: luciolacorreia@gmail.com, ORCID: https://orcid.org/0000-0001-9916-3958

\author{
ART ICLE INFO \\ Article history: \\ Received 2020-06-01 \\ Accepted 2020-11-30 \\ Available online 2020-11-30
}

\begin{abstract}
Palavras-chave: Transgêneros, Transexuais, Cultura Participativa, Instagram, Influenciadores.

Keywords:

Transgender, Transsexuals, Participatory Culture, Instagram, Influencers.
\end{abstract}

RESUMO. Estimulado pelo surgimento de dispositivos portáteis e acessíveis como smartphones equipados com câmeras digitais, o sujeito da contemporaneidade acessa e cria conteúdos de maneira autônoma, motivado, à princípio, pela maleabilidade e instantaneidade desses novos aparatos tecnológicos. Visto que os antigos modos de se criar produtos midiáticos priorizavam apenas retratar padrões tradicionalistas e invisibilizavam a existência da transgeneridade ou do transativismo, surge um movimento independente, dentro das redes sociais, que através de imagens e textos, vai legitimar a presença transgênero no convívio social. Esse estudo objetivou traçar um panorama da quantidade de perfis que atualmente abordam tais questões, dentro do Instagram, e que encontram-se produzindo para este público específico. Através do uso da Netnografia, a pesquisa resultou na observação de duas personalidades de relevância na plataforma, e a partir deste recorte, constatou-se que a necessidade de ocupação desses espaços on-line reside no desejo de inspirar seus seguidores a assumirem suas identidades de gênero e lutarem por sobrevivência também fora da Internet.

ABSTRACT. Stimulated by the emergence of portable and accessible devices such as smartphones equipped with digital cameras, the contemporary subject accesses and creates content autonomously, motivated, at first, by the malleability and immediacy of these new technological devices. Since the old ways of creating media products prioritized only portraying traditionalist patterns and made the existence of transgender or transactivism invisible, an independent movement emerges, within social networks, which through images and texts, will legitimize the transgender presence in social life. This study aimed to provide an overview of the number of profiles that currently address such issues, within Instagram, and that are being produced for this specific audience. Through the use of Netnography, the research resulted in the observation of two personalities of relevance on the platform, and from this cut, it was found that the need to occupy these online spaces lies in the desire to inspire their followers to assume their identity. gender and fight for survival also outside the Internet.

\section{Introdução.}

A sociedade atual atravessa uma profunda modificação na forma de se comunicar na contemporaneidade, relações interpessoais reconfiguram-se para meios remotos e proporcionam a sensação de proximidade entre os agentes comunicadores, visto que o acesso se dá livre de barreiras físicas, tornando a produção de conteúdo na internet massificada, espontânea e cada vez mais veloz. De acordo com Martino (2014. p. 37) com o surgimento de comunidades em rede e ferramentas de conteúdo gerado pelo usuário, o 
espectador compreende a oportunidade de reivindicar maior representação dentro desenvolvimento dos produtos audiovisuais veiculados junto aos seus pares, e através da informação disseminada de maneira igualitária.

No momento em que surge o ciberespaço, o fluxo contínuo de dados pode ser alimentado por todos aqueles que compõem esse universo dentro da Internet e contribuem para torná-lo uma extensão das vivências que já se davam fora deste ambiente, naquilo que Levy (1999, p. 10) vai chamar de Cultura Participativa. Constitui-se, dessa forma, uma reorganização da estrutura da produção de conteúdo midiático dentro do novo milênio, expectadores que anteriormente apenas absorviam o que era ditado pela cultura de massa nos meios clássicos de comunicação, começaram a opinar, criar perfis, discursos textuais e imagéticos.

Por outro lado, o sentimento de representatividade de vários segmentos do público que consome mídia, não é recente, nem nasce com o surgimento da Internet e das novas tecnologias, assim como diversas nuances da coexistência social foram ressignificadas após a massificação dos aplicativos e diversificação dos discursos, percebemos, na atualidade, movimentos em busca de maior democratização e quebra de estereótipos impostos em épocas anteriores.

A medida que os meios de produção de conteúdo se tornam ferramentas de utilização livre, emergem movimentações nítidas na desestabilização do sistema de valores em vigência por muito tempo na nossa sociedade, que prezava pela desumanização e mínimo espaço de debate sobre os direitos de determinadas minorias defendidos por grupos ideológicos e sociais, tais quais: O movimento negro, o feminismo e a causa LGBTQ+. Ainda bastante conflituosa é a aceitação, por parte majoritária da sociedade, do convívio e inserção das pessoas transexuais dentro do mercado de trabalho, da naturalização de suas relações interpessoais, e da desvinculação do estigma de transtorno mental entre indivíduos que não se sentem confortáveis nos papeis do gênero que lhe foi $\neg$ imposto, uma vez que:

Identidade de gênero é o gênero com o qual uma pessoa se identifica, que pode ou não concordar com o gênero que lhe foi atribuído quando de seu nascimento (...) uma pessoa pode nascer com um sexo biológico (homem ou mulher) e se identificar com o gênero oposto (masculino ou feminino). Orientação sexual é atração afetivosexual por alguém, vivência interna relativa à sexualidade (heterossexual, homossexual ou bissexual). Identidade de gênero e orientação sexual são dimensões diferentes, que não devem ser confundidas (SILVA, et al, 2015. pag.2)

O não esclarecimento sobre essas questões gera a incompreensão das lutas dos trangêneros dentro escopo geral da sociedade, visto que tais pessoas se percebem como presas a uma identidade que não lhes pertence. Este fato, de per si, já repercute na rejeição por parte de quem não vive o dilema.

Complexificando ainda mais os aspectos dessas subjetividades, Silva et al (2015), vai 
estabelecer que dentro do grupo dos trangêneros existem os travestis, que é a classificação dada a pessoas do sexo masculino e traços ainda masculinizados, mas que não se identificam com os papeis atribuídos socialmente a esse gênero. Mulheres transexuais que são nascidas com o sexo biológico masculino, mas que possuem a real convicção de que são mulheres, inclusive se submetem a cirurgias de redesignação de gênero, enquanto que os homens transexuais, são pessoas nascidas com o sexo feminino, mas que também não concordam com essa condição e passam por mudanças corporais em função disso. Dentro do grupo das pessoas transgênero também existem indivíduos que transitam entre os dois gêneros ou na neutralidade entre eles, conhecidos como "não-binários".

Nos meios comunicacionais anteriores, lidar com essa multiplicidade de experiências, não interessava ao modelo de cultura heterossexual dominante, entretanto, com a democratização na produção de conteúdo, com a facilidade de manuseio das ferramentas audiovisuais nos celulares e com o imediatismo de postagens na Internet, essa situação se reverte no aumento de páginas produzidas por transgêneros, num processo de formação de um movimento que estabelece identidades e se fortalece na empatia com outras pessoas em iguais circunstâncias ao redor do mundo, na identificação fortalecida pelas imagens e experiências compartilhadas.

Diante desta nova realidade, é imprescindível que a comunidade acadêmica volte o seu olhar para a pesquisa deste universo de apreciação: A visibilidade que é dada aos transgêneros através da criação de perfis no Instagram sobre essa temática. As redes sociais são o principal meio impulsionador na formação dessas identidades, visto que a liberdade dos usos nos suportes gera, por consequência, o maior número de usuários participando do processo de maneira autônoma. Existem inúmeras redes que possuem uma capacidade aglutinadora de seguidores bastante volumosa, entretanto, o Instagram, atualmente, lida com toda a carga simbólica que envolve a imagem: enquanto que o discurso escrito evoca do imaginário, a fotografia e o vídeo funcionam como espécie de "espelho do real" (DUBOIS, 1994, p.45).

Esses suportes, ainda que passíveis de edições ou polissemias, proporcionam a experiência maciça do expectador se identificar através da materialidade da imagem, na prova irrefutável de que aquele discurso é legítimo, já que a fotografia é a chancela da veracidade, algo que é fator primordial na formação das comunidades de seguidores e na criação da identidade visual desses grupos.

O objeto de estudo Instagram e a potência transativista dos discursos nesta rede proporcionam diversos vieses para análise que não se esgotam apenas nesta pesquisa isoladamente, a critério de recorte temático para melhor apreciação, dentro dos objetivos específicos, verificamos as principais hashtags que aglutinam comunidades de seguidores nesse universo, e em seguida, selecionamos dois dos perfis de relevância dentro da hierarquia do aplicativo, para averiguarmos de que maneira esses usuários utilizam-se do discurso 
imagético em prol de seus ideais, e por fim, reconhecemos de que maneiras esses recursos auxiliam a chancelar a reivindicação por mais visibilidade social para a comunidade transgênero.

Como resultados, constatou-se através das próprias ferramentas de busca do aplicativo e contagem de seguidores, que a quantidade de perfis de pessoas transgênero na web possui números significativos e tende a crescer à medida que suas publicações são vistas e assimiladas sem os filtros da mídia tradicional e que a profusão de imagens e vídeos afirmando essas vivências fortalece a representação e construção dessas identidades no convívio social.

\section{Metodologia.}

O percurso metodológico para essa análise fundamenta-se na abordagem experimental de pesquisas qualitatitvas e quantitativas (FRAGOSO, et al. 2011) em redes sociais na internet, focando não apenas em um único método, mas na compilação de diferentes conceitos que tentam elucidar as estruturas decorrentes de interações dos atores sociais, compreendendo os elementos básicos sobre os seguidores e influenciadores formados nessas redes.

Dentro desta estrutura, pretendemos utilizar enquanto critério de escolha no banco de dados do Instagram, em primeiro lugar: As redes formadas por hashtags de maior relevância para a cultura transgênero, e em seguida: Dois perfis elencados de acordo a popularidade entre o público do aplicativo e citações a respeito do tema, que são os perfis de Rosa Luz e Lucca Najar.

Outra abordagem significativa proposta por Hine (2000, p.15) supõe a análise da internet dentro dessas duas perspectivas: Enquanto artefato cultural e enquanto Mídia, o que justifica a escolha específica dos personagens na análise: São personalidades que usam a ferramenta como disseminação de suas vivências e produtos culturais, e que também se apropriam do Instagram como instrumento midiático, se estabelecendo enquanto influências do discurso militante.

Todas essas apreciações baseam-se na metodologia etnográfica antropológica, algo que expande a análise estrutural da rede para outros campos do conhecimento por fornecerem, segundo Fragoso, et al (2011, p. 45): "uma estrutura para pensar sobre aspectos do cyberspaço que podem ser observados como campos para um etnógrafo". Isso nos leva ao desenvolvimento de uma Etnografia Virtual (FRAGOSO, RECUERO, AMARAL, 2011) ou Netnografia (KOZINETS, 2010), que consiste na análise do comportamento de indivíduos e grupos sociais dentro do cyberespaço, acompanhando suas dinâmicas e cujas consequências 
extrapolam para o off-line. Nessa perspectiva, vamos analisar os discursos verbais e imagéticos no sentido de contribuir para representatividade da cultura transexual.

\section{Desenvolvimento.}

As questões de gênero e todas as suas nuances e reivindicações ainda não pacificadas na sociedade perpassam necessariamente pelo próprio conceito de gênero e suas transformações ao longo do tempo, culminando nos movimentos de diversidade. O conceito foi construído para explicar as interações estabelecidas entre os homens e mulheres socialmente, os papéis que cada um assume, e as relações de poder instituídas entre eles para além da condição e determinação biológica: "Falar sobre gênero nos leva a uma profunda reflexão pautada em um contexto biológico e sociocultural imposto a todos". Santos (2016, p.10).

Ainda na atualidade, a tradição dos costumes patriarcais intrinsicamente ligados às nossas características na sociedade em geral, se faz presente em todas as instituições. Costumes estes, que colocaram o gênero masculino no papel da liderança incólume e no status de força, poder e superioridade sob o único gênero oposto: O feminino. Santos (2016, p. 10), ainda pontua que esses papeis traçam "uma noção de que o homem ocupa seu lugar como personagem dominante, enquanto as mulheres encontram-se subjugadas aos ideais atribuídos historicamente e assegurados, sobretudo, por instituições como igreja, cultura, e pela sociedade". Quanto mais arraigada às reminiscências tradicionais deste patriarcalismo, mais complexa se torna a desestabilização dos papeis do homem e da mulher para esta realidade social, uma vez que essas verdades são postas como naturais e, sobretudo, de ordem divina:

Levando em consideração a crença de que o corpo é um atributo natural e que define a identidade de homens e mulheres enquanto pessoas de um sexo ou de outro, as mudanças corporais realizadas pelas travestis e transexuais implicam em dificuldade de convivência nos espaços sociais normatizados. (SILVA, et al 2015. Pag. 3)

Em sociedades, comunidades e instituições ainda presas às amarradas da herança colonial e religiosa, tais quais as brasileiras, é tortuoso o processo de aceitação de pessoas que nascem aprisionadas a um gênero, mas optam por pertencer a outro, ou a nenhum gênero pré-determinado:

A não aceitação familiar os leva a morarem outros ambientes. O acesso aos serviços de saúde, às políticas públicas e à circulação, em diferentes territórios e instituições, também é dificultado. Sem muita opção de moradia e meios de se sustentar, podem ir viver no contexto da rua e da noite e encontrar na prostituição um meio de sobrevivência, o que os coloca em situação de risco (SILVA, et al 2015. Pag. 3). 
Nota-se em pesquisa recente promovida pelo grupo Gay da Bahia, que o Brasil teve registros de "445 assassinatos por orientação sexual em 2017 e é o país que mais mata transexuais no mundo, de acordo com a Transgender Europe (TGEU)" (LUPI, 2018), ainda que existam subnotificações sobre os dados em países da Ásia, Africa e Oceania, o número é considerado alarmante e essa situação já é suficiente para a luta constante por reconhecimento, não só por parte de todo o ciclo de convivência que perpassa a vida da pessoa transexual, como até mesmo no difícil processo de auto aceitação e superação do medo de assumir-se diante da intolerância e violência dentro desta realidade.

De maneira contraditória, diversos estudos comprovam a existência dessas pessoas desde séculos anteriores em diferentes locais e épocas. Historicamente, constam registros de pessoas transgênero desde a antiguidade, GREEN (1998) cita dois poetas romanos Manilo e Juvenal, que aludiam a homens que viviam e se comportavam como mulheres, exibindo certa repulsa ao serem vistos como do gênero oposto. A historiadora Emily Skidmore, descobriu que há aproximadamente 120 anos, pessoas nascidas como mulheres se vestiam e se identificavam como homens, em localidades remotas nos Estados Unidos (BOTELHO, 2017). Lili Elbe, famosa mulher trans do início do século XX, cujo nome de batismo era Einar Wegner, foi uma das pioneiras dentro dos tratamentos médicos de redesignação. Sua história foi retratada no filme A Garota Dinamarquesa (Focus Features, 2015).

A partir do momento que a internet democratiza a comunicação e dá voz a esses casos, rompe-se o modelo midiático anterior, em que o público trans não possuía a representação adequada e era marginalizado pela cultura hegemônica, visto que as grandes empresas de comunicação e produtores de cinema não tinham o costume de desafiar e causar desconforto nas crenças dominantes de sua audiência. Dentro das redes, e posteriormente, fora delas, eclode a visibilidade a esses casos e por consequência, o desejo de aceitação e inclusão das pessoas trans dentro das leis, das relações de trabalho e convivência pacificada.

\section{Resultados e Discussão.}

Nos diversos aplicativos, sobretudo no Instagram, o uso das Hashtags permite a categorização das publicações de forma organizada, gerando comunidades de perfis dentro de um mesmo tema (SALLES, 2019). Utilizando o marcador "\#” dentro dos assuntos que se deseja enfatizar sobre a imagem, ela torna seu conteúdo detectável e permite que os usuários localizem rapidamente outras publicações relevantes com interesses em comum. A escolha por esse sistema, se deu por razão de refinar as buscas dentro da temática e também por proporcionar o recorte para perfis brasileiros, cujos costumes e crenças estão mais próximos 
do público de abrangência deste estudo, entretanto, as palavras \#trans, \#transgender, \#transdayofvisibility e \#transisbeautiful também estão entre as mais usadas pelos brasileiros na comunidade mundial.

Realizando a busca na ferramenta para determinar as palavras específicas dentro do próprio Instagram, que elenca em quantidade de seguidores que utilizaram determinada "etiqueta" - tradução para a palavra hashtag - percebeu-se que as categorizações mais usadas por perfis brasileiros, em agosto de 2019, são: \#trânsgênero, com 106k, ou cento e seis mil, perfis de seguidores, \#mulhertrans com 20.4k de seguidores, \#transbrasil com 18k de seguidores e \#homenstrans com 1000+ de seguidores. Vale ressaltar também, a relevância do termo \#naobinario com 5000+ de seguidores, e a constatação de que o termo \#semgenero aglutina diversos elementos que não fazem parte do universo LGBTQ+ ou que até sem posicionam contra as teorias de gênero.

A seleção dos dois perfis da análise se deu por observação das matérias de maior relevância no sistema de Search Engine Optmization do Google (MESQUITA, 2017), publicadas em sites sobre a popularidade de determinados perfis transexuais na rede. Alguns perfis possuem maior número de seguidores, como o @Mandycandyreal, perfil de uma mulher trans influenciadora dos segmentos de moda e beleza, entretanto, além da popularidade, a quantidade de postagens sobre a a própria condição, como fator de militância, foi o norteador da pesquisa observacional enquanto mídia e artefato da cultura de gênero. (HINE, 2000).

\subsection{Rosa Luz @Rosadobarraco.}

Rosa Luz é uma mulher trans negra de 23 anos, nascida na periferia do Distrito Federal e atualmente morando na cidade de São Paulo. Começou a produzir conteúdo sobre sua rotina e o processo de aceitação de sua real identidade através do YouTube, em 2016, e migrando para o Instagram no mesmo ano. Artista visual, compositora e cantora de Rap, a influencer possui um perfil com mais de 29 mil seguidores onde disponibiliza fotos, vídeos e interage com o público, não apenas sobre a condição transgênero, mas também abordando temas como: raça, classe e a experiência de ter crescido na periferia. Rosa se identifica como travesti, no sentido de desvincular o tom pejorativo ligado ao termo, e exaltar o processo de luta que essas pessoas enfrentam ao decidirem assumir-se para sociedade, família e para si mesmas. O conteúdo do Instagram exalta fotos em primeiro plano da artista, em poses que demonstram orgulho, elementos artísticos, livros e símbolos imagéticos que reforçam o seu discurso militante, à primeira vista, antes mesmo de se acessar os textos. A página também apresenta vídeos com suas performances, músicas com trechos autobiográficos e sessões de destaques paras os conteúdos mais completos em outras plataformas, esses fatores imediatamente transmitem a mensagem de aceitação para outras pessoas que buscam o 
perfil da Rosa Luz a fim de compreender melhor como é existir e sobreviver dentro do contexto de pobreza e preconceito, e de ser aceita enquanto pessoas trans que busca encontrar outras alternativas que fujam da prostituição e marginalidade.
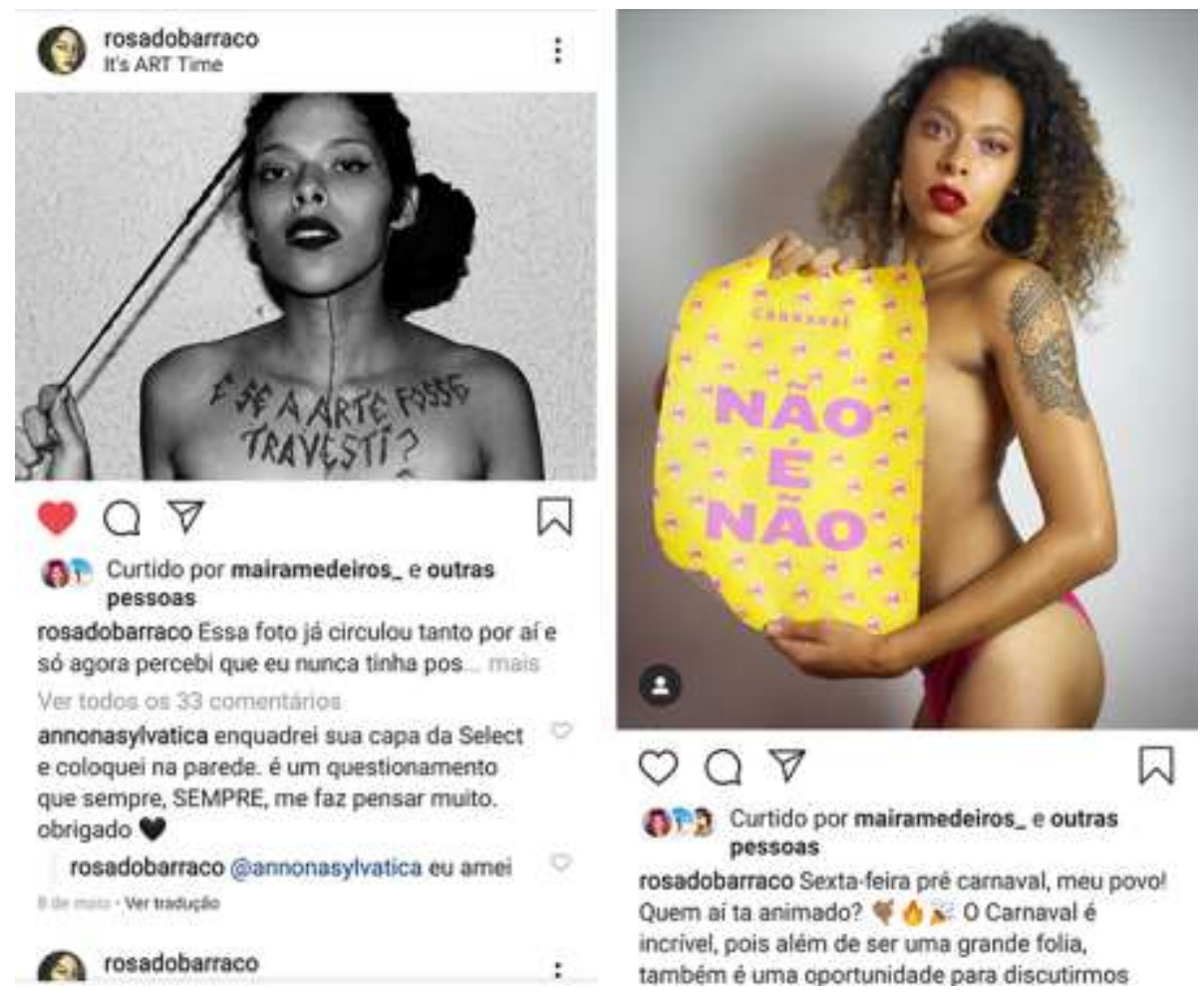

\section{Imagem 1 - Fotos do perfil de Rosa Luz no Instagram com manifestações ativistas}

Fonte: Perfil do Instagram @roosadobarraco.

Em suas postagens Rosa explica sobre as pressões que sofreu na faculdade ao decidir assumir-se travesti, preconceito de professores, ameaças de grupos de ódio on line, e a dificuldade de inserção no mercado de trabalho. As respostas em suas publicações, entretanto, reforçam de maneira positiva que o apoio do público é crescente e entusiasmado, comprovando que sua mensagem vem sendo assimilada exponencialmente na rede.

\subsection{Lucca Najar @Lucca.Najar.}

Lucca Najar é um homem transexual nascido em Belo Horizonte, de 27 anos, e que possui um perfil no Instagram com mais de 37 mil seguidores. Até os 24 anos, Lucca vivia como mulher. $O$ influenciador explica em seus vídeos, postagens e entrevistas, que não compreendia perfeitamente o desejo de se parecer fisicamente com o pai durante sua infância. 
Já na fase da adolescência, criava perfis masculinos falsos na Internet para enfim poder viver a nova identidade que lhe era desejada, porém não permitida socialmente. Na vida adulta, percebeu a dificuldade de encontrar roupas que não se enquadrassem na binaridade dos gêneros e foi a partir destes conflitos, e após o contato com outras histórias semelhantes na internet, que Lucca entendeu a necessidade de ser assumir transexual. Em conjunto com sua formação de Videomaker, decidiu criar o canal no YouTube em 2016. Diante da popularidade de seus vídeos e a migração do público para o Instagram, no mesmo ano, também conectouse nesta rede. As postagens são detalhadas: Lucca possui destaques em que fala dos estágios da transição para o corpo masculino, os hormônios que se deve aplicar, o custo e seus efeitos físicos, a relação com a família e namorada, uma sessão para pergunta dos seguidores, e as complicações no momento de escolher os médicos para a cirurgia de redesignação de gênero: A mastectomia. Outro fator importante constatado nesta observação, é que ao se acessar a timeline das imagens, imediatamente percebe-se que se trata de um perfil engajado na causa LGBTQ+, em função dos símbolos e cores que se referem a este universo, imediatamente perceptíveis, antes mesmo de se ver os depoimentos e os textos:

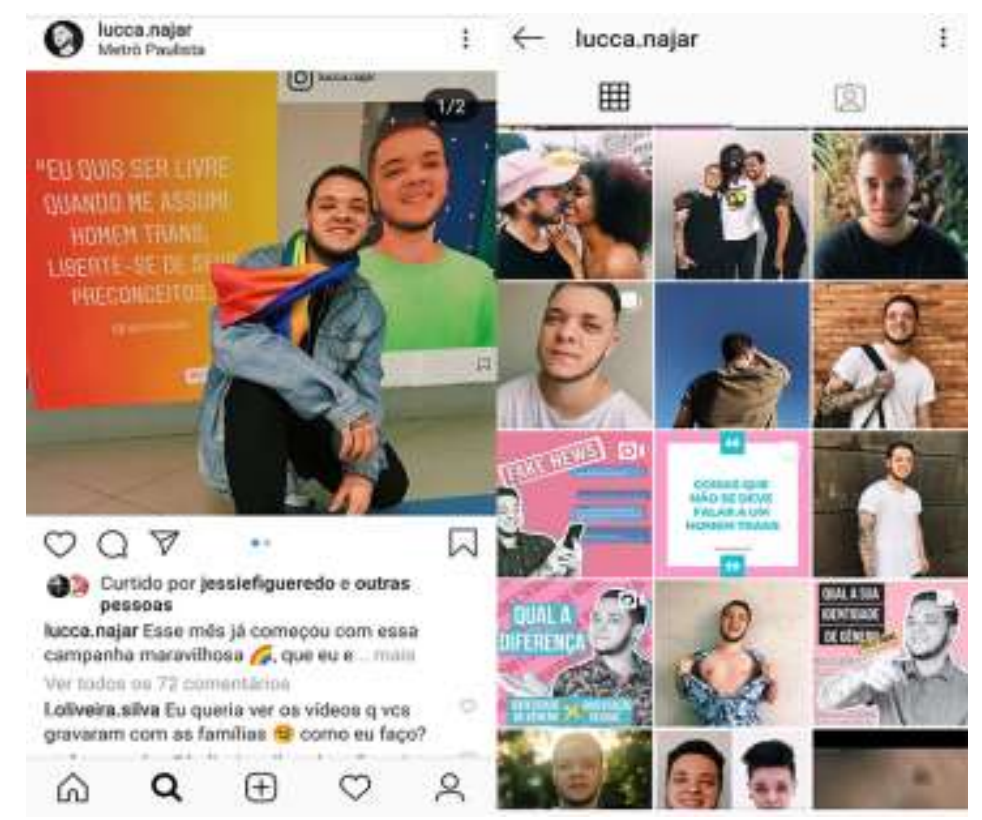

Imagem 1 - Fotos do perfil de Lucca Najar no Instagram com manifestações ativistas

Fonte: Perfil do Instagram @lucca.najar.

O público responde de maneira ativa no perfil do influencer, através de elogios, mensagens de apoio e perguntas. A possibilidade de interação direta por comentários e enquetes estimula na criação de mais conteúdo e incentiva diretamente na publicação de perfis semelhantes, conforme declarado por Lucca em um de seus vídeos publicados. Ele também exibe seu corpo, após a transformação, o que leva seu expectador a perceber que o 
sucesso da transição corporal pode, e deve, ser desmistificada e bem-sucedida.

\section{Conclusão.}

Após o estudo netnográfico e observacional fornecido pelo banco de dados de etiquetas relacionadas a gênero, redesignação e transexualidade disponível na plataforma Instagram, nota-se a multiplicidade de histórias dentro da Internet que abordam essas questões e anseiam por visibilidade e representação. Nos exemplos identificados através das hashtags específicas, os perfis se colocam abertos para a apreciação do público, de forma a demarcar presença e assim desestabilizar antigos padrões impostos pela cultura patriarcal, tradicionalista e que se fez dominante ao longo da história. O uso do percurso metodológico neste estudo faz-se adequado dentro de várias propostas de pesquisas sobre a formação de comunidades autônomas na Internet.

Ressalta-se também, a importância do surgimento do cyberespaço para as discussões tomarem corpo e alcançarem o receptor ideal desse tipo de mensagem, que por sua vez também pode tornar-se disseminador do mesmo conteúdo. A democratização do meio audiovisual produz um sistema de retroalimentação que se expande de forma transmidiática, criando um repositório constantemente atualizado com novos relatos em textos, vídeos e fotografias, dentro das perspectivas da inteligência coletiva. A utilização das imagens é a potência simbólica definitiva de se afirmar enquanto ser transgênero, conforme identificado nas fotos e vídeos produzidos pelos dois perfis do Instagram escolhidos: O público acessa as imagens impregnando-as da chancela da realidade e, neste sentido, acreditam em sua legitimidade, reproduzindo também esses discursos.

Esse movimento não organizado formalmente, porém alinhado dentro dos mesmos valores simbólicos, desvela os caminhos propostos dentro deste corpus. Retomando os autores citados anteriormente a respeito dos dogmas sociais e tradicionalistas, a tendência natural, durante muitos anos em nossa história, era a marginalização dessas subjetividades, contudo, ao se fazerem presentes na rede social, as pessoas transgênero reafirmam o desejo de representatividade como presença, como militância e como garantia de sobrevivência. 


\section{Referências}

A Garota Dinamarquesa. Direção de Tom Hooper. Los Angeles: Focus Features, 2015. 1 DVD (119 min.).

BOTELHO, Raquel. Pesquisadora conta em livro 120 anos de histórias de homens trans.

Disponível em: <https://www1.folha.uol.com.br/equilibrioesaude-120-anos-de-historia-dehomens-trans.shtml> acesso em jul. de 2019.

DUBOIS, Philippe. O ato fotográfico e outros ensaios. Papirus Editora, 1994.

FRAGOSO, S.; RECUERO, R; AMARAL, A. Métodos de pesquisa para internet. Porto Alegre: Sulina, 2011.

GREEN, R. Mythological, historical and cross-cultural aspects of transsexualism. New York: Garland Publishing; 1998.

HINE, Christine (org.) How can qualitative Internet Researchers define the boundaries of their Project? Conversations about method. p. 01-20. Los Angeles: Sage, 2009.

KOZINETS. Robert V. Netnography. Doing Ethnographic Research Online. Disponível em: $<$ https://www.researchgate.net/publication/267922181_Netnography_Doing_Ethnographic_R esearch_Online> acesso em 07 de jun. de 2019.

LÉVY. Pierre. Cybercultura. Tradução: Carlos Irineu da Costa. São Paulo: Editora 34. 1999. LUPI, Leonardo. Jornal do Brasil: Orgulho e Preconceito. Disponível em: <https://www.jb.com.br/pais/artigo/2019/07/1012067-orgulho-e-preconceito.html> acesso em 07 de jan. de 2019.

MARTINO, Luis Mauro Sá: Teoria das Mídias Digitais: Linguagens, Ambientes e Redes. Rio de Janeiro: Vozes Editora, 2014.

MESQUITA, Renato. O que é SEO: o guia completo para você entender o conceito e executar sua estratégia. Disponível em: < https://rockcontent.com/blog/o-que-e-seo/> acesso em 02 de jun. de 2019.

NÁPOLLES, Katarina. Entenda como funciona o novo algoritmo do Instagram. Disponível em: < https://postgrain.com/blog/algoritmo-instagram/> acesso em 14. mai. de 2019

SALLES, Filipe. 6 ferramentas para encontrar melhores hashtags do Instagram no seu segmento. Disponível em: <https://www.apptuts.com.br/tutorial/redes-sociais/ferramentasencontrar-melhores-hashtags-instagram-segmento/> acesso em 10 ago. de 2019.

SANTOS, Patrícia Nogueira Costa. Sobre a teoria do agendamento, gênero e publicidade. Disponível em: <http://dspace.bc.uepb.edu.br/jspui/handle/123456789/10338> acesso em 10 de ago. de 2019.

SILVA, et al. Os impactos das identidades transgênero. Rev Ter Ocup Univ São Paulo. 2015 set.-dez.;26(3):364-72. 